\title{
Acessibilidade textual e terminológica: promovendo a tradução intralinguística
}

DOI: http://dx.doi.org/10.21165/el.v49i1.2775

\author{
Maria José Bocorny Finatto'
}

\section{Resumo}

Este artigo situa e divulga uma nova tendência de pesquisa em Terminologia, pelo menos no âmbito brasileiro, a qual tende a extrapolar o usual reconhecimento de termos e de conceitos para a organização de glossários, dicionários ou base de dados terminológicos. Seu foco são questões associadas à promoção da acessibilidade textual e terminológica, buscando-se orientações linguísticas, teóricas e metodológicas para guiar processos de composição de textos facilitados sobre temas científicos e tecnológicos dirigidos para diferentes perfis de usuários-leitores. Será destacado aqui o atendimento de necessidades de informação de trabalhadores adultos com escolaridade limitada e pouca experiência de leitura.

Palavras-chave: Terminologia; simplificação textual e terminológica; acessibilidade.

1 Universidade Federal do Rio Grande do Sul (UFRGS), Porto Alegre, Rio Grande do Sul, Brasil; maria.finatto@gmail.com; https://orcid.org/0000-0002-6022-8408 


\title{
Textual and terminological accessibility: promoting intralinguistic translations
}

\begin{abstract}
This paper deals with a new research trend in Terminology, at least in the Brazilian context, which tends to extrapolate the usual recognition of terms and concepts for the organization of glossaries, dictionaries or terminological databases. It focus on issues associated with the promotion of textual and terminological accessibility, placing linguistic, theoretical, and methodological guidelines to guide processes of composition of facilitated texts on scientific and technological themes directed to different user-reader profiles. It will be highlighted here the meeting of information needs of adult workers with limited education and little reading experience.
\end{abstract}

Keywords: Terminology; textual and terminological simplification; accessibility.

\section{Introdução}

Este artigo ${ }^{2}$, que corresponde ao tema de uma palestra proferida durante o $67^{\circ}$ Seminário do GEL, pretende situar e divulgar uma nova vertente de pesquisa em meio aos estudos brasileiros de Terminologia, conforme sistematizados, por exemplo, por Barros (2004) e por Krieger e Finatto (2017). Essa nova tendência caracteriza-se por extrapolar o reconhecimento de termos e de conceitos para a organização de glossários, dicionários ou base de dados terminológicos, ocupando-se do funcionamento textual do léxico especializado em meio a um todo de significação e de comunicação.

O caráter inovador, além da ultrapassagem do limite da sistematização do léxico terminológico, dá-se também pela consideração sobre o funcionamento de um todo de texto, em sua sintaxe e semântica, em meio às suas dimensões discursiva e comunicativa. Nesse sentido, a descrição do texto, do léxico em geral e das terminologias nele empregados visa a colher subsídios para a promoção da acessibilidade textual e terminológica (doravante ATT). Para potencializar a ATT, colocam-se orientações linguísticas e metodológicas que possam guiar processos de composição de textos facilitados para diferentes perfis de usuários-leitores. Em meio a esse cenário de estudos, teoricamente embasado e orientado a uma aplicação específica, destacam-se aqui questões relacionadas à promoção da acessibilidade de textos escritos em português

2 Este texto não é completamente original, pois sintetiza dados da palestra proferida durante o $67^{\circ}$ Seminário do GEL, ocorrido em 2019. Além disso, aproveita partes do capítulo de livro Acessibilidade Textual e Terminológica: um novo tópico de pesquisas em Terminologia no Brasil, publicado pela Editora Pontes como volume II da obra Estudos Geossociolinguísticos do Português Brasileiro, organizado por Abdelhak Razky da UFPA, em 2020. 
sobre temas de Saúde e sobre temas de Utilidade Pública para leitores brasileiros que sejam trabalhadores entre 25 e 55 anos de idade, com escolaridade limitada e pouca experiência de leitura.

Assim, o ponto de partida de nossos estudos atuais sobre ATT, empreendidos em meio a um grupo de pesquisa ${ }^{3}$ junto ao PPG-LETRAS da Universidade Federal do Rio Grande do Sul (UFRGS) é a descrição linguístico-terminológica de corpora compostos por coleções de textos de divulgação científica escritos por especialistas para leigos. Entretanto, experiências anteriores com o estudo de textos oriundos de jornais populares, dirigidos justamente para a população de menor poder aquisitivo, fornecem uma base sempre importante para a ATT. Maiores informações sobre esses jornais e um corpus aberto podem ser obtidas junto ao Projeto PorPopular, em http://www.ufrgs.br/textecc/ porlexbras/porpopular/.

Atualmente, com base em descrições de textos de divulgação sobre temas de Saúde e sobre diferentes assuntos de interesse público, buscamos dados sobre perfis de escrita mais e menos complexos, em diferentes aspectos. A partir disso, avaliamos diferentes processos de uma "reescrita para a simplificação" que favoreçam a compreensão de leitura. Esses processos envolvem a adaptação do léxico, das terminologias e do todo da tessitura textual, da sintaxe à semântica do texto, aproximando-o de um padrão da "língua escrita" que possa ser mais familiar a leitores do perfil antes citado, uma pessoa adulta trabalhadora com apenas o Ensino Fundamental completo com pouca experiência de leitura. Para tanto, diferentes processos e estratégias de simplificação textual são testados tendo-se em vista uma aproximação com a ideia de uma "tradução intralinguística" (ZETHSEN, 2009; JAKOBSON, 2012 [1959]). Com esse encaminhamento investigativo, buscamos refletir sobre a promoção da acessibilidade mediada por um tal tipo de "tradução".

Este artigo, após apresentar um dada situação-problema e conceitos-chave, sintetiza alguns de nossos estudos sobre ATT junto ao Projeto TEXTECC (http://www.ufrgs.br/ textecc/), mencionando os seguintes:

a) a pesquisa intitulada "Acessibilidade Textual e Terminológica", que lida com a facilitação de textos da área de Saúde e de outras áreas de interesse público;

b) a investigação "Terminologia Histórica", na qual se estudam textos antigos de Medicina, escritos em português no século XVIII, publicados, justamente, para auxiliar pessoas que tratavam de doentes e que tinham "erudição" limitada;

3 Ver dados do nosso grupo de pesquisa em Acessibilidade TT em http://www.ufrgs.br/textecc/. 
c) simplificação linguístico-terminológica sobre temas de Saúde em Libras - Língua Brasileira de Sinais.

O artigo é concluído com a indicação de perspectivas e de desafios para um tal tipo de investigação em seus desdobramentos. São feitas também algumas considerações sobre a tradução interlinguística frente à tradução intralinguística.

\section{A situação-problema: não basta ler, tem que entender}

Conforme se pode verificar pela leitura do trecho a seguir, que trata sobre "Fibrose cística" e que integra uma Portaria do Ministério da Saúde do Brasil (doravante MS), um texto desse tipo poderia representar algumas dificuldades de compreensão de leitura. As potenciais dificuldades, imaginando-se um leitor relativamente bem letrado, como o que costuma ler e escrever artigos de Linguística, tenderiam a incidir sobre a terminologia. Entretanto, cabe frisar, este tipo de texto é destinado a profissionais de Saúde. Além disso, está em meio a um verdadeiro manual de procedimentos para a parte clínica e laboratorial e farmacêutica do atendimento a pacientes acometidos por tal doença. Mas, ainda assim, imaginemos que, por algum motivo, um linguista precise ter acesso às informações nele contidas. Vejamos o trecho a seguir:

\section{Introdução}

Fibrose cística, também chamada de mucoviscidose, é uma doença genética autossômica recessiva. Embora predomine na população caucasiana, com incidência de 1:3.000 nascidos vivos, pode estar presente em todos os grupos étnicos (1). No Brasil, a incidência ainda é ignorada, contudo estudos regionais mostram dados estatísticos variáveis que sugerem uma incidência em torno de 1:7.000 no país como um todo (2). A vida média dos pacientes com fibrose cística tem aumentado nos últimos anos, alcançando a terceira década, resultado do diagnóstico precoce e do tratamento especializado instituído nas fases iniciais da doença (3).

Fibrose cística é uma doença multissistêmica, sendo o acometimento pulmonar responsável pela maior morbimortalidade dos pacientes. 0 acúmulo de muco nas vias aéreas inferiores é uma das características-chave da fisiopatogenia da doença pulmonar, assim como a presença de reação inflamatória predominantemente neutrofílica e infecção bacteriana. As alterações pulmonares iniciam nas vias aéreas menores e são progressivas, evoluindo para o surgimento de bronquiectasias, fibrose pulmonar e cor pulmonale. Os principais componentes do muco viscoso das vias aéreas dos pacientes com fibrose cística são a mucina e o pus derivado do DNA (ácido ribonucleico) intracelular liberado pela degranulação dos neutrófilos (4) 
Fonte: Protocolo Clínico e Diretrizes Terapêuticas. Fibrose Cística - Manifestações Pulmonares Portaria SAS/MS n 224, de 10 de maio de 2010. (Retificada em 27.08.10). Disponível em: http://portalarquivos.saude.gov.br/images/pdf/2014/ abril/02/pcdt-fibrose-cistica-manif-pulm-retificado-livro-2010.pdf. Acesso em: 19 set. 2019:

Vamos supor, agora, um texto, também do MS, sobre o mesmo tema, cujo leitor-alvo é, desta vez, em tese, um cidadão comum em busca de informações sobre o tema. Suponhamos, novamente, a sua leitura por um linguista:

Fibrose Cística (FC), também conhecida como Doença do Beijo Salgado ou Mucoviscidose, é uma doença genética crônica que afeta principalmente os pulmões, pâncreas e o sistema digestivo. Atinge cerca de 70 mil pessoas em todo mundo, e é a doença genética grave mais comum da infância. Um gene defeituoso e a proteína produzida por ele fazem com que o corpo produza muco de 30 a 60 vezes mais espesso que o usual. O muco espesso leva ao acúmulo de bactéria e germes nas vias respiratórias, podendo causar inchaço, inflamações e infecções como pneumonia e bronquite, trazendo danos aos pulmões. Esse muco também pode bloquear o trato digestório e o pâncreas, o que impede que enzimas digestivas cheguem ao intestino. 0 corpo precisa dessas enzimas para digerir e aproveitar os nutrientes dos alimentos, essencial para o desenvolvimento e saúde do ser humano. Pessoas com fibrose cística frequentemente precisam repor essas enzimas através de medicamentos tomados junto às refeições, como forma de auxílio na digestão e nutrição apropriadas.

Fonte: Fibrose Cística. Biblioteca Virtual em Saúde. Ministério da Saúde. Disponível em: http://bvsms.saude.gov.br/dicas-em-saude/2675-fibrose-cistica. Acesso em: 19 dez. 2019:

Ao ler esses dois textos, um colega linguista ou mesmo um estudante de Letras poderá experimentar diferentes dificuldades de processamento da informação oferecida. 0 primeiro texto, em tese, tenderia a oferecer maiores dificuldades por conta de um discurso especializado e de um cenário comunicativo específico. Ainda assim, o uso de dicionários e de fontes de apoio seria um aliado, somando-se a isso os seus conhecimentos sobre o funcionamento e a morfologia do português. Desse modo, esse leitor poderia "decifrar" o sentido de, por exemplo, "doença genética autossômica recessiva". Já, no segundo texto, conforme supomos, a compreensão tenderia a ser mais fácil, sobretudo se ele fosse lido após o primeiro. Nele, o item "muco" seria já conhecido, ainda que interpretar "trato digestório" pudesse significar alguma consulta a um dicionário ou mesmo ao Google.

Entretanto, conforme demonstram recentes pesquisas, as dificuldades de um "leitor comum" - o público em geral - tendem a ser muito maiores do que as de um leitor linguista. Aliás, podemos dizer que elas tendem a ser estratosfericamente maiores. Dizemos isso 
porque, conforme o INAF (2018), apenas 12 entre cada 100 pessoas, no Brasil, teriam condições de entender plenamente o segundo texto, que é justamente "dirigido para público leigo". Entre essas 12 pessoas estariam quantos linguistas?

Dados do INAF, gerados em pesquisas, podem ser alvo de críticas quanto a metodologias utilizadas. Mas, ainda bem, há toda uma vasta e importante bibliografia disponível sobre o tema. Quanto à compreensão de Leitura, especialmente no âmbito da Psicolinguística do Brasil, há toda uma trajetória de estudos para nos ajudar a confirmar suspeitas sobre a complexidade dos textos para diferentes leitores aqui exemplificados. Nessa direção, vale mencionar que tal assunto já esteve em trabalhos de importantes e pioneiros pesquisadores brasileiros de Linguística Aplicada, especialmente no âmbito do ensino de línguas estrangeiras (LEFFA, 1996) e de ensino de língua portuguesa na Educação Básica (PERINI, 1982; FULGÊNCIO; LIBERATO, 1998). Essas reflexões, entre outras mais atuais que se poderia mencionar (como PEREIRA; BARETTA, 2018), via de regra, associaram perfis de textos didáticos, vocabulário, reflexões sobre Leitura e graus de proficiência leitora de aprendizes escolares, especialmente jovens e crianças. No âmbito da divulgação científica em jornais, vale citar o trabalho de Motta-Roth e Scherer (2016).

Essa "gradação" constitutiva da complexidade de um texto é sempre algo relativo. A CT pode ser consubstanciada no seu plano lexical, frasal e terminológico, frente à potencial dificuldade de compreensão para diferentes leitores, com distintas bagagens de conhecimentos. Em meio a textos escritos que tratam de temas importantes, perguntamonos, com afinco, como contribuir para que adultos de escolaridade limitada possam ser atendidos em suas necessidades de informação. Como informações importantes podem chegar, de um modo compreensível, via texto escrito, à maioria da população brasileira? Esse é nosso problema de pesquisa e essa é uma necessidade real e imediata, conforme busca ilustrar a Figura 1 a seguir. 


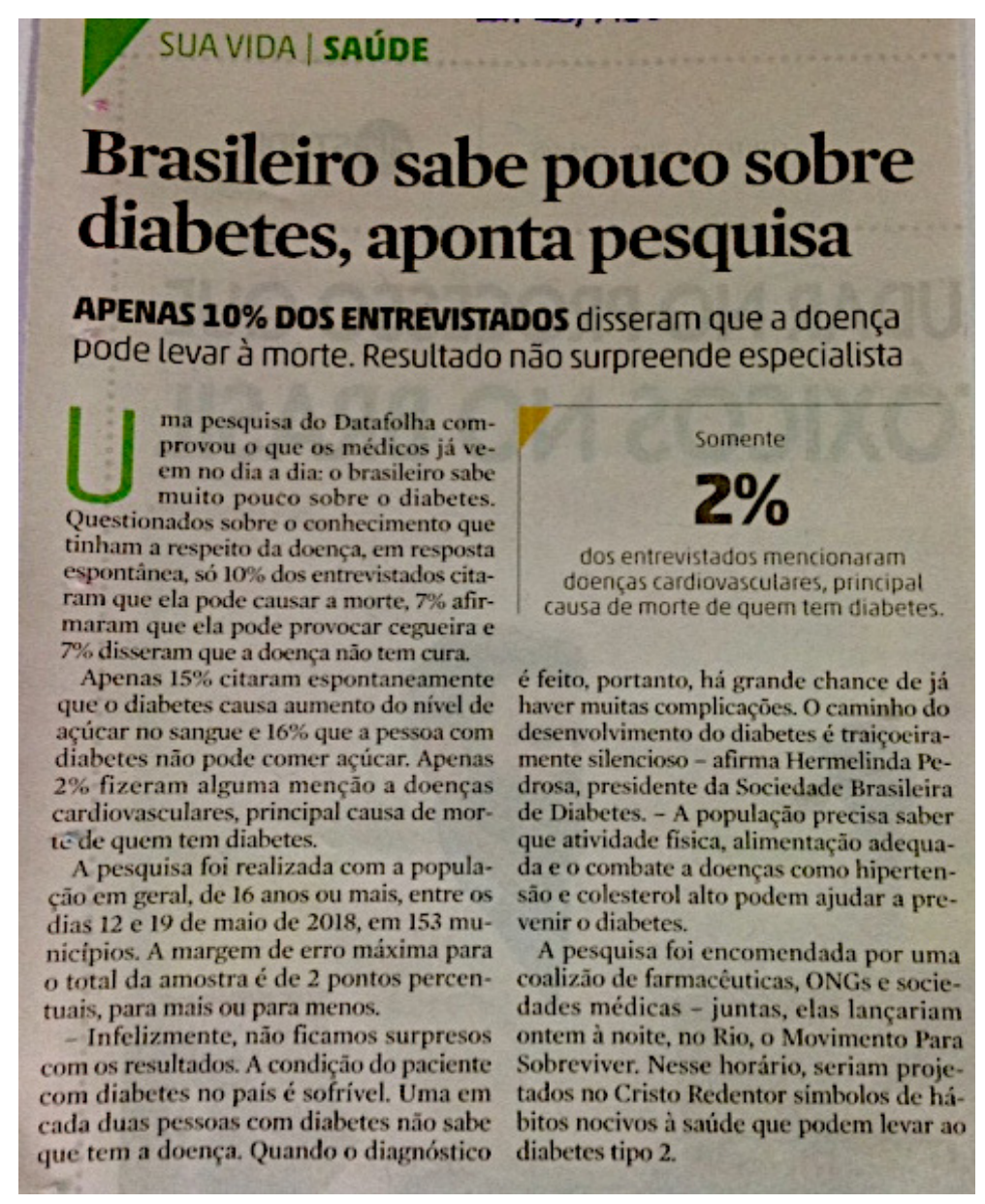

Figura 1. Notícia: Brasileiro sabe pouco sobre diabetes

Fonte: Jornal Zero Hora, em 25/7/2018

Conforme a notícia da Figura 1, a população brasileira pouco parece compreender o conceito associado ao termo "diabetes". Ora, se é verdade que a população "precisa saber", como declara uma médica entrevistada na notícia, caberia perguntar: de que modo tal população será instruída? Investir na escola pública e no ensino de qualidade parece ser a primeira resposta. Por outro lado, enquanto não temos a causa primordial desse problema resolvida, bem sabemos, há várias campanhas do nosso MS, com farta oferta de material escrito sobre esse tema e sobre tantos outros, seja na internet, na TV ou em folhetos informativos entregues a quem procura nossas Unidades Básicas de Saúde.

Nesse cenário, o reconhecimento é universal entre os profissionais de Saúde Pública, a prevenção é a medida que melhor equaciona qualidade de vida, investimentos e gastos. Mas como e por que motivos, ainda assim, as pessoas não conseguem entender coisas tão importantes em meio ao que lhes é oferecido como informação? Essa pergunta 
também já tem sido formulada, há um bom tempo, por pesquisadores da área da Saúde, como vemos no trabalho de Miranda e colaboradores (2009) sobre dificuldades e compreensão de Termos de Consentimento em um Centro de Estudo de Hematologia e Oncologia. Mas, além do que já mencionamos, haveria alguma resposta escondida em algo do que nos mostra o texto da Figura 2 a seguir?

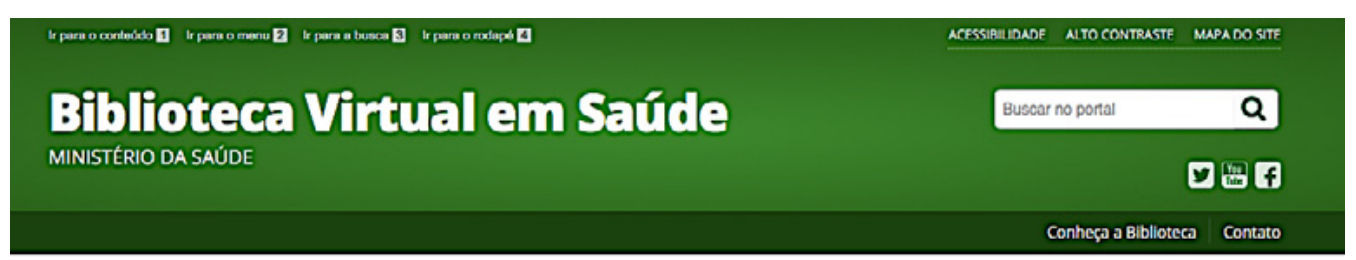

\begin{tabular}{|c|c|}
\hline SOBRE A BVS & ete \\
\hline O que é a BVS & blicado: Quarta, 09 de Setembro de 2015, $12 \mathrm{~h} 11$ | Acessos: 9632 \\
\hline Comitê Consultivo & \\
\hline Outras BVS & \multirow{2}{*}{$\begin{array}{l}\text { Diabetes Mellitus (DM) é uma síndrome metabólica de origem múltipla, decorrente da falta de insulina e/ou da } \\
\text { incapacidade de a insulina exercer adequadamente seus efeitos. A insulina é produzida pelo pâncreas e é } \\
\text { responsável pela manutençăo do metabolismo da glicose e a falta desse hormônio provoca déficit na } \\
\text { metabolização da glicose e, conseqúentemente, diabetes. Caracteriza-se por altas taxas de açúcar no sangue } \\
\text { (hiperglicemia) de forma permanente. }\end{array}$} \\
\hline $\begin{array}{l}\text { SERVICOS DA } \\
\text { BBBLIOTECA }\end{array}$ & \\
\hline $\begin{array}{l}\text { Carta de Ser } \\
\text { ao Cidadão }\end{array}$ & Tipos: \\
\hline $\begin{array}{l}\text { Comutação } \\
\text { Bibliográfica }\end{array}$ & \multirow{2}{*}{$\begin{array}{l}\text { - Tipo 1: causada pela destruiçăo das células produtoras de insulina, em decorrência de defeito do sistema } \\
\text { imunológico em que os anticorpos atacam as células que produzem a insulina. Ocorre em cerca de } 5 \text { a } 10 \% \text { dos } \\
\text { diabéticos. }\end{array}$} \\
\hline & \\
\hline PRODUTOS DA BVS & $\begin{array}{l}\text { - Tipo 2: resulta da resistência à insulina e de deficiêneia na secreçăo de insulina. Ocorre em cerca de } 90 \% \text { dos } \\
\text { diabéticos. }\end{array}$ \\
\hline & \multirow{6}{*}{$\begin{array}{l}\text { - Diabetes Gestacional: é a diminuiçăo da tolerância à glicose, diagnosticada pela primeira vez na gestação, podendo } \\
\text { ou não persistir após o parto. Sua causa exata ainda não é conhecida. } \\
\text { - Outros tipos: são decorrentes de defeitos genéticos associados com outras doenças ou com o uso de } \\
\text { medicamentos. Podem ser: defeitos genéticos da funçăo da célula beta; defeitos genéticos na açăo da insulina; } \\
\text { doenças do pâncreas exócrino (pancreatite, neoplasia, hemocromatose, fibrose éstica, etc.); induzidos por drogas } \\
\text { ou produtos químicos (diuréticos, corticóides, betabloqueadores, contraceptivos, etc.). } \\
\text { Principais sintomas do DM tipo 1: vontade de urinar diversas vezes; fome frequente; sede constante; perda de }\end{array}$} \\
\hline $\begin{array}{l}\text { Boletim } \\
\text { Informacăo para a }\end{array}$ & \\
\hline $\begin{array}{l}\text { Informaçăo para a } \\
\text { Saúde }\end{array}$ & \\
\hline Datas da Saúde & \\
\hline Dicas em Saúde & \\
\hline Eventos & \\
\hline
\end{tabular}

Figura 2. Texto do Ministério da Saúde do Brasil (MS) sobre "Diabetes".

Fonte: http://bvsms.saude.gov.br/dicas-em-saude/2052-diabetes.

Acesso em: 21 out. 2019

Este texto, acreditamos, fala por si, pois deveria poder ser compreendido por qualquer cidadão brasileiro. Ele é oferecido pelo nosso MS. Afınal, se há um trecho potencialmente complexo, como "síndrome metabólica de origem múltipla, decorrente da falta de insulina e/ou da incapacidade de a insulina exercer adequadamente seus efeitos", também há tentativas de aproximação com o leitor comum com o segmento "Caracteriza-se por altas taxas de açúcar no sangue (hiperglicemia) de forma permanente". Não obstante, podemos (re)colocar as seguintes perguntas: como facilitar a compreensão de um modo homogêneo, em todo o texto? Como as pessoas encarregadas desse tipo de divulgação costumam ser orientadas? No que os Estudos da Linguagem e os de Terminologia podem contribuir para esse tipo de trabalho? 
Sintetizando, vale dizer que, no nosso caso particular de estudos, ilustrando esse novo tipo de orientação de pesquisa em Terminologia, interessam a descrição e a análise de textos institucionais disponíveis on-line sobre temas de Utilidade Pública produzidos para o consumo de leitores brasileiros adultos de escolaridade limitada e pouco hábito de leitura. Como protótipo de leitor, consideramos o/a cidadão(ã) adulto(a), com idade entre 25 e 55 anos, trabalhador(a) das classes socioeconômicas C e D. A seguir, trazemos alguns conceitos importantes em meio à nossa pesquisa.

\section{Conceitos-chave: acessibilidade, compreensão e "leiturabilidade"}

Justamente porque os tópicos da acessibilidade ou inteligibilidade (em inglês reunidos sob a denominação readbility, conforme DUBAY, 2004), simplificação e complexidade textual estão relacionados e até imbricados, parece haver uma certa confusão sobre seus escopos, especialmente por parte de quem se interessa pelo assunto em Terminologia. Em função disso, queremos contribuir para situá-los. Assim, nas próximas seções, associamos essas noções com os textos de divulgação científica para leigos que mais nos interessam.

\subsection{Complexidade, simplificação, acessibilidade e ferramentas}

A Complexidade Textual (doravante CT) pode ser entendida como uma propriedade ou condição relativa de um dado texto para um dado tipo de leitor ou usuário. Essa condição, associada a um entendimento do texto escrito por parte do leitor-alvo, poderá ser verificada ou percebida ou mesmo justificada em função da presença de alguns componentes ou de recursos - como tema e estilo do texto, uso de terminologias, de vocabulário, tipo de organização sintática ou de tipos de frases, entre outros elementos. Um trabalho pioneiro sobre esse tema é o livro de Rudolf Flesch, de 1949, que tratou justamente de uma escrita que pudesse ser compreensível por diferentes leitores (cf. FLESCH, 1949).

Assim, a CT conforma-se pela presença e combinação de um conjunto de recursos ou de propriedades de uma dada escrita que a tornam mais ou menos complexa para o entendimento e/ou bom processamento de um determinado perfil de leitor. Entre os recursos estruturais passíveis de conferir algum tipo de CT, estão, no âmbito do léxico e da formulação estrutural, o número de palavras, a quantidade de palavras por frase, a extensão geral do texto, a relação type-token (ou medida de riqueza lexical, que se refere à quantidade de palavras novas ou repetidas em um texto), a presença de referências pronominais, quantidade e escopo de anáforas, elipses, grau de narratividade, nível necessário de inferência de sentenças para compreensão, quantidade de terminologia específica que possa fugir do vocabulário comum para um dado perfil de leitor, presença de vocabulário pouco familiar, entre outros. 
No âmbito de uma verificação de prováveis elementos promotores de CT, podem ser observados, de modo extensivo e com apoio computacional mais ou menos sofisticado, diferentes fatores, especialmente quanto ao léxico e à sintaxe. Nesse tipo de enfoque vemos, em ação, os recursos da Estatística Linguística combinados com os das metodologias da Linguística de Corpus e do Processamento da Linguagem Natural, em tipos de análise como as que já apontamos em um trabalho sobre a complexidade de artigos científicos de Pediatria (FINATTO, 2011). Entretanto, sempre se estará tratando de uma estimativa, a qual somente poderá ser confirmada em testes diretos com os leitores-alvo de um dado texto.

Uma tal metodologia de análise lexicológica, com apoio estatístico e computacional, foi introduzida no Brasil em 1967 pela saudosa professora e pesquisadora, entusiasta da cooperação entre estudiosos de Linguística e de Computação, Maria Tereza C. Biderman (ver BIDERMAN, 1967, 1978, 1996). Ela foi a primeira que auxiliou a perceber e tratar, quantitativa e qualitativamente, uma série de elementos da superfície ou da tessitura do texto escrito a partir de corpora.

Entre esses elementos a observar, temos as frequências de termos e de palavras ou de expressões de um dado texto $X$ em contraste com aquelas verificadas em acervos textuais que servem para representar um dado perfil léxico e gramatical em um dado recorte espaço-tempo. Nesse tipo de enfoque léxico-estatístico, também tendem a ser examinados, entre diferentes elementos que potencializam a CT, a presença de estrangeirismos, o uso de estruturas gramaticais mais complexas (como a voz passiva) ou mais simples (como a voz ativa e ordem direta tipo Sujeito-Verbo-ObjetoCircunstância), etc.

Por sua vez, a Simplificação Textual (ST) pode ser compreendida como um processo, uma ação de reformulação. Pode ser realizada via escrita ou fala e incluir imagens e/ou recursos audiovisuais. No caso do texto escrito, refere-se a procedimentos reconhecidos como necessários, após uma verificação de provável percepção de CT para um dado leitor-alvo. O processo de simplificação, associado a uma reescrita, pode ser subjetivo, baseado em impressões ou em conhecimentos diversos do redator, ou poderá ser guiado por uma série de procedimentos e de critérios científicos, previamente estabelecidos e mensurados. Uma maneira singela e facilmente imaginável para se dar suporte à simplificação do texto, restrita ao léxico, seriam dicionários ou "listas" de substituições, nos quais se colocariam, por exemplo, as seguintes entradas: "ingerir=> comer"; "nosocômio=> hospital".

Todavia, a despeito da singeleza do exemplo, vale dizer que já contamos no Brasil e no mundo com importantes pesquisas nesse tema, principalmente no âmbito do Processamento da Linguagem Natural (PLN), um ramo da Ciência da Computação. Fora do Brasil, já contamos, por exemplo, com uma versão simplificada dos textos em inglês 
da Wikipedia, conforme mostra a Figura 3, além de haver sistemas como o SIMPLISH, um gerador automático de textos simplificados disponível em: https://www.simplish.org.

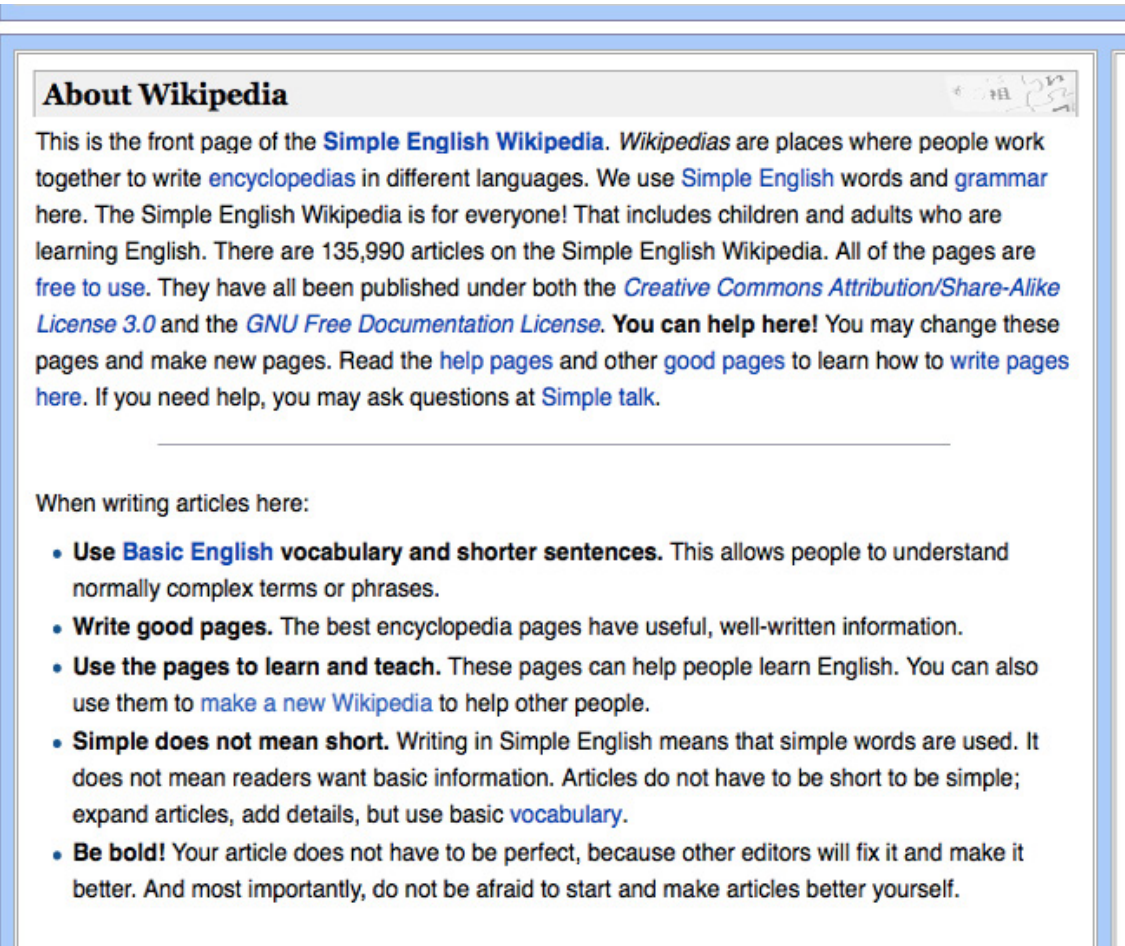

Figura 3. Wikipédia simples.

Fonte: https://simple.wikipedia.org/wiki/Main_Page. Acesso em: 21 out. 2019.

Um exemplo de sistema brasileiro que, de modo automático, também dá suporte a procedimentos de ST em português é o SIMPLIFICA. Esse sistema pioneiro é uma referência internacional, fruto do Projeto PorSimples - trabalho sintetizado por Aluísio e Gasperin (2010). As ferramentas que integram o sistema, que operam no âmbito lexical e sintático, podem ser visualizadas em http://www.nilc.icmc.usp.br/nilc/index.php/toolsand-resources?layout=edit\&id=27. Seu funcionamento, ainda que o site da ferramenta possa exibir alguns problemas técnicos, pode ser verificado a partir do que buscamos ilustrar na Figura 4 a seguir: 


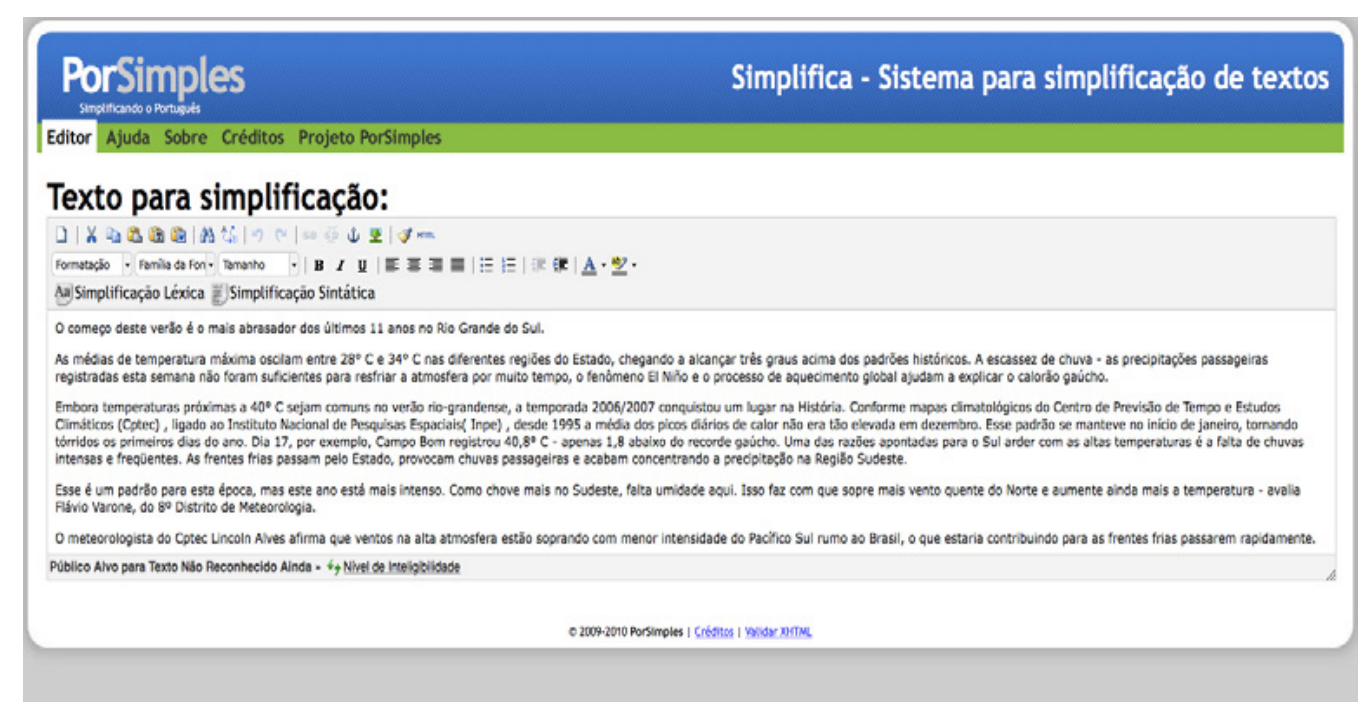

Figura 4. Sistema SIMPLIFICA, do Projeto PorSimples do NILC-USP

Fonte: http://www.nilc.icmc.usp.br/simplifica/. Acesso em: 21 out. 2019.

A ST, seja subjetiva ou cientificamente amparada, pode gerar condições para que se possa promover a ATT. Essa acessibilidade pode ser compreendida como algo que não é nem condição, nem processo, mas, sim, um ideal de bom funcionamento de um dado tipo de texto para um dado perfil de leitor. Esse ideal é o que se buscaria alcançar, por exemplo, no cenário comunicativo de folhetos informativos impressos sobre um dado tema de Saúde Pública, como o Sarampo ou Diabetes, entregues a uma dada população em meio a campanhas de Saúde Pública.

Diversos são os processos de simplificação que podem ser aplicados a um texto de temática científica que se apresente, em potencial, originalmente complexo para um leitor brasileiro adulto com escolaridade limitada e pouco hábito de leitura. Todos, entretanto, serão dirigidos e modelados conforme as necessidades do público-alvo, os recursos disponíveis para a (re)apresentação do texto e da mensagem e os propósitos da comunicação via escrita. Em termos de promover maior ou menor compreensão leitora, os processos linguísticos e cognitivos envolvidos são, conforme se reconhece na literatura científica de Linguística, Educação, Psicologia e Psicolinguística, muito diversos. Contudo, a maior ou menor acessibilidade abrangerá aspectos que podem ir além daqueles que se encontram no nível linguístico-textual - ela pode ser, por exemplo, relacionada ao design e à organização "concreta" do texto em si, como espaçamentos, tamanhos, cores e tipos de fontes, presença de imagens, etc., o que se associa ao termo legibilidade. Quaisquer processos de simplificação que se decida lançar mão, vale frisar, devem respeitar as características do público para o qual o texto será destinado. Caso contrário, o texto, e principalmente seu conteúdo/informação, serão sumariamente desprezados pelo leitor. 
Nesse contexto, a ATT pode ser vista como uma condição desejada, resultante de processos de escrita ou de reescrita que partem de um texto-fonte, ou de uma informação-fonte, em tese, complexos. Essa "complexidade original" estimada e da qual se parte como referência tende a ser, também, multifatorial, podendo ser construída por conteúdos, convenções de escrita, etc. Por outro lado, em sendo a ATT uma condição ou qualidade, é algo que, uma vez realizado, poderá ser identificado pelo uso/presença adicional de diferentes elementos facilitadores de compreensão, tais como são, por analogia, as rampas de acesso para cadeirantes que vemos em prédios públicos.

Esse processo de promoção de acessibilidade pode envolver, também, uma produção escrita que já nasça, originalmente, com o objetivo de ser simplificada ou acessível, com alto potencial de "leiturabilidade". Assim, embora as ideias de complexidade e acessibilidade pareçam ser, à primeira vista, imbricadas, pode-se fazer uma tentativa didática de distinção: a "complexidade" refere-se a uma condição ou estado, verificados através de uma avaliação. A "simplificação", por sua vez, diz respeito ao processo de transformação do texto, com o objetivo de torná-lo mais eficiente. Por fim, a "acessibilidade" pode ser compreendida como uma condição-resultado dessa ação.

Embora diferentes estudos tenham sido desenvolvidos no âmbito dos Estudos de Leitura e da Linguagem sobre os temas da legibilidade, da acessibilidade e compreensibilidade ou "leiturabilidade", não há uma conclusão, uma "regra de ouro" ou uma fórmula mais ou menos fixa que garanta, de antemão, o sucesso de uma simplificação textual. Será sempre preciso testar, diretamente com os leitores-alvo, se uma compreensão qualificada foi atingida. Nessa via, é vital repetir: é fundamental conhecer previamente o perfil do leitor que se pretenda atender.

Por fim, é importante reforçar que a simplificação de um texto que trate, por exemplo, de temas científicos nem sempre estará destinada apenas para públicos leigos e com baixo grau de escolaridade. Inúmeras vezes, textos científicos altamente complexos precisam ser simplificados também para graduandos universitários, para outros tipos de aprendizes e mesmo para pessoas com necessidades especiais.

Todos esses usuários podem ser considerados pertencentes ao perfil de "semileigo", pois ainda não têm, em tese, conhecimentos suficientes para lidar com textos complexos ou de "conteúdo avançado", especialmente se forem textos que trazem muitas terminologias, sem maiores contextualizações sobre os conceitos a que correspondem. Valeria o mesmo raciocínio para o atendimento de leitores que são estudantes de línguas estrangeiras com diferentes graus de proficiência, ou para a elaboração de materiais educativos inter ou multidisciplinares, dirigidos para profissionais de áreas correlacionadas a uma dada área. Assim, o redator ou o "redator-simplificador", geralmente conhecido, no âmbito dos estudos de Terminologia, como um profissional que faz o trabalho de "redator técnico", precisará tomar decisões de escrita e de (re)formulação que possam ser eficientes em diferentes cenários comunicativos. 


\subsection{Estudos de Terminologia e ATT: dois exemplos}

Apresentamos, de modo resumido, dois estudos concluídos no nosso grupo de pesquisa, os quais se ocuparam da descrição de textos institucionais de temática científica voltados para público leigo.

O primeiro estudo (CARPIO, 2017) pode ser considerado um derivativo da pesquisa "Pneumopatias Ocupacionais: padrões da linguagem médica para leigos e especialistas" - cujas produções, em termos de glossários e de diferentes tipos de descrições de linguagens especializadas, podem ser conferidas no Projeto TextPneumo, nos websites: http://www.ufrgs.br/textecc/textpneumo/ e http://www.ufrgs.br/textecc/pneumopatias/ novafase/index.php.

Carpio (2017), nesse trabalho ${ }^{4}$, tratou de textos elaborados pelo Ministério da Saúde (MS) sobre o amianto e as doenças provocadas pela sua inalação. Através de um canal específico de comunicação, a autora solicitou, oficialmente, ao MS, que the fossem indicados quais textos sobre esse tema o MS havia produzido para atender especificamente ao público leigo. O propósito do trabalho foi descrever a feição dos textos e caracterizar o público-leitor alvo preferencial da informação. Ao identificarem-se eventuais fatores textuais que pudessem potencializar a CT, seriam propostas adaptações que fossem, em tese, adequadas aos leitores-alvo, trabalhadores do setor de indústria e da construção civil expostos às poeiras do amianto.

A pesquisa revelou várias características que tornam esses materiais potencialmente inadequados para a compreensão do leitor. E, ao final do estudo, traz um modelo de folheto informativo, em tese, mais afeito à compreensão dos trabalhadores. O modelo de melhorias apresentado incluiu, além de aspectos linguísticos e terminológicos, recomendações de modos de apresentação da informação indicados por uma médica especialista que trata de pacientes acometidos por Pneumopatias Ocupacionais na Santa Casa de Misericórdia de Porto Alegre - RS. Vale frisar que essa instituição é referência na área e recebe pacientes de todo o Brasil.

O segundo exemplo é o trabalho de Fetter (2017 e 2018). Nele, a autora descreveu a apresentação de terminologias, de acordo com padrões oracionais, em textos divulgativos e educacionais de instituições de assistência agropecuária destinados a agricultores familiares brasileiros, os quais tendem a ter uma experiência de escolaridade

4 Trabalho desenvolvido no âmbito do projeto "Recuperação da informação em representação do conhecimento em bases de textos científicos de Linguística e de Medicina: padrões e processamento automático da linguagem", por nós coordenado, financiado pelo Programa DOCFIX, FAPERGS-CAPES, entre 2012 e 2016, Edital 09/2012, com a participação da Profa. Dra. Alena Ciulla, atualmente docente do PPG-LETRAS-UFRGS, a qual orientou o trabalho citado. 
formal bastante limitada. O corpus de estudo da pesquisa foi composto por 30 folhetos da Associação Riograndense de Empreendimentos de Assistência Técnica e Extensão Rural (EMATER-RS), o qual foi confrontado com um corpus de 30 folhetos da Empresa Brasileira de Pesquisa Agropecuária (EMBRAPA). A descrição e a análise empreendidas pela autora partiram de pressupostos teóricos da Terminologia de perspectiva textual (cf. FINATTO, 2004) e da Linguística Sistêmico-Funcional.

Foram examinadas 4.850 orações dos 60 folhetos sob estudo. 0 trabalho apontou alguns elementos que potencializam a CT desses materiais, especialmente o modo de apresentação frasal e as naturezas das terminologias empregadas. A descrição empreendida visou também indicar, ainda que resumidamente, algumas alternativas de escrita ou reescrita teoricamente mais úteis para uma ampliação da ATT desses materiais. Uma síntese desse trabalho, na parte do tratamento sistêmico-funcional das terminologias, pode ser conferida em Fetter (2018).

\section{Acessibilidade textual e terminológica e tradução intralinguística}

Desde 2018, estamos explorando o entendimento de que simplificação textual poderia ser entendida também como um tipo de "tradução", uma tradução intralinguística, conforme Jakobson (2012 [1959]) já havia delineado. Essa direção ficou reforçada como uma boa opção quando percebemos que: a) a "lógica" por trás de diferentes ferramentas automáticas de simplificação - como o já citado SIMPLIFICA - ser muito semelhante à da tradução automática tradicional; b) outros estudiosos da Tradução já vinham acolhendo esse pensamento (como ZETHSEN, 2009; ZEHTSEN, HILL-MADSEN, 2016).

Nessa via, além de textos sobre temas de Saúde destinados para o público em geral, estamos examinando também a linguagem jurídica que mais precisaria alcançar o entendimento do "cidadão comum". Nesse segmento, escolhemos tratar do texto das Sentenças dos Juizados Especiais Cíveis (JECS). Esses juizados especiais, popularmente conhecidos como "tribunais de pequenas causas", integram um cenário relativamente novo de assistência judiciária mais facilitada, ao qual se pode ter acesso sem o auxílio de um advogado. Uma ATT necessária poderia pode ser presumida no âmbito dessas Sentenças e demais materiais escritos fornecidos para quem procura os JECS, pois, afinal de contas, esses tribunais baseiam-se em princípios como a informalidade e a simplicidade, tendo sido criados para ampliar e facilitar o acesso à Justiça.

Visto que muitos dos que recorrem ao JECS tendem a ser pessoas de baixa renda, com pouca experiência de leitura e escolaridade limitada, a reflexão que se recoloca é sobre como, por meio de procedimentos de simplificação textual, poder-se-ia promover a ATT também desses documentos. Essa pesquisa deverá ser concluída também com a apresentação de propostas de reescrita, as quais deverão ser colocadas em um guia especialmente dirigido para juristas e para os redatores que os auxiliem. A proposta 
original dessa pesquisa e um estudo-piloto com um conjunto de Sentenças podem ser conferidos no artigo de Motta (2018).

Ainda que a temática jurídica não se relacione, diretamente, com nossos estudos sobre a ATT em textos sobre temas de Saúde, as considerações dela derivadas e os contrastes propostos nos auxiliam a ponderar sobre as necessidades do nosso protótipo de leitor. Assim, se o cenário, as temáticas e os gêneros textuais sob estudo variam, do Direito, passando pela Agricultura Familiar, até a Medicina e ainda outros, há em comum a figura do mesmo leitor-destinatário, um brasileiro adulto de escolaridade limitada.

\subsection{Referências de um português escrito mais simples}

Resultados iniciais de estudos com Sentenças dos JECS revelaram que elas tendem a apresentar padrões lexicais e sintáticos pouco coincidentes com padrões da linguagem escrita de um jornal popular. Esse não é um resultado surpreendente, mas esperaríamos que pudesse ser diferente. Depois desse primeiro contraste com esse tipo de jornal, o universo vocabular das mesmas Sentenças foi também comparado com o universo lexical do CorPop (PASQUALINI, 2018), o qual é um corpus de referência do português popular escrito, disponível para consulta em http://www.ufrgs.br/textecc/. Esse corpus foi especialmente planejado para dar suporte a tarefas de simplificação de textos para leitores brasileiros adultos de escolaridade limitada.

Acreditamos que o CorPop pode servir como uma referência sobre o que possa ser um universo vocabular acessível para um leitor adulto que tenha apenas o Ensino Fundamental completo e que precise compreender, por exemplo, textos sobre Diabetes do MS ou as Sentenças dos JECS. Quanto ao que contém o CorPop, vale explicar que ele está composto por:

(1) textos do jornalismo popular (Diário Gaúcho);

(2) textos e autores mais lidos pelos respondentes das últimas edições da pesquisa Retratos da Leitura no Brasil;

(3) textos da coleção "É Só o Começo", que envolveu adaptação de clássicos da literatura brasileira para leitores com baixo letramento, adaptação produzida por linguistas, estudiosos de Literatura Brasileira e tradutores;

(4) textos do jornal Boca de Rua, produzido por pessoas em situação de rua, que vivem em Porto Alegre - RS. É um jornal impresso, em formato tradicional, produzido por pessoas com baixa escolaridade e baixo letramento. Todo o material veiculado conta com a supervisão de uma jornalista responsável; e, 
(5) textos do Diário da Causa Operária, veículo da imprensa operária brasileira, um jornal produzido também por pessoas dentro da faixa média de letramento dos leitores do nosso país.

\subsection{Propostas para reescrita(s) e simplificação}

Uma vez identificada a potencial CT, assim como encontramos potenciais boas práticas de escrita, resta o trabalho de propor melhorias "estruturais" e de testar o seu sucesso com os leitores-alvo. Essas tarefas, associadas ao estudo da ATT, buscamos resumir em um artigo (FINATTO; PONOMARENKO; BERWANGER, 2019) recentemente publicado na revista Roseta, um novo veículo da ABRALIN - Associação Brasileira de Linguística. Essa revista é especialmente dedicada à popularização da Linguística no Brasil e solicita, aos autores, textos "em linguagem simples".

Um trabalho do nosso grupo que buscou reconhecer, justamente, as melhores estratégias para uma redação simplificada de textos sobre temas de Saúde, foi a pesquisa de Silva (2018). Nela, foram examinados textos de divulgação para leigos que tratam do tema do Transtorno do Estresse Pós-traumático (TEPT). Pela via dos estudos do Léxico e de Terminologia, foram descritos e analisados artigos de divulgação disponíveis na internet. O diferencial desse estudo, além do exame de textos em português, é trazer algumas questões e análises sobre materiais equivalentes produzidos em inglês para o público norte-americano. Ademais, para cada um dos textos em português sob exame, o pesquisador apresenta oito diferentes propostas de reescrita. Cada proposta pretende colocar "em teste" um determinado tipo de estratégia de apresentação do texto e incide, inicialmente, sobre itens de potencial CT apontados na bibliografia sobre o assunto e que tenham sido, de algum modo, já incluídos na arquitetura de ferramentas computacionais como o sistema COH-METRIX, já apresentado em Finatto (2011) e em Scarton e Aluísio (2010).

Os elementos textuais sob exame por Silva (2018) foram: i) índice Flesch (IF), análise semântica latente (ASL), relação type-token (TT), densidade semântica (DS), incidência de substantivos (S), incidência de verbos $(V)$, incidência de adjetivos (ADJ), incidência de advérbios (ADV) e incidência de pronomes (P). Cada uma das propostas de reescrita dos textos sob exame foi avaliada com o auxílio de ferramentas computacionais que exibem medidas estimativas de CT. Esse é um trabalho que tem servido como uma importante referência para o nosso grupo de pesquisa.

Outros estudos e materiais associados ao nosso grupo podem ser conferidos em: http://www.ufrgs.br/textecc/acessibilidade/page/publicacoes/. 


\section{Perspectivas, desafios e novos temas de estudo}

Cada vez mais, interessamo-nos pelo tema da ST como um tipo de tradução intralinguística. Atualmente, estamos ocupados em simplificar textos institucionais sobre a Doença de Parkinson - em Neurologia - e sobre Cuidados com a Criança - em Pediatria. As versões simplificadas, construídas com base na bibliografia disponível, criticadas por profissionais da Saúde e testadas com leitores-alvo, abastecem uma base de dados e uma base de informações para compartilhamento com pesquisadores interessados. Naturalmente, o CorPop, antes citado, oferece uma referência sobre vocabulário mais simples, assim como o trabalho de Silva (2018) nos orienta sobre estratégias de reescrita.

A base de dados, com o trabalho que estamos investindo, em diferentes frentes de estudo e pesquisa, torna possível o oferecimento de uma série de informações, que tentamos reunir em um site especialmente dedicado ao tema da ATT (http://www. ufrgs.br/textecc/acessibilidade/page/index/). Além disso, as experiências que tivemos, tanto com o Processamento da Linguagem Natural (PLN) quanto com a Linguística de Corpus (FINATTO, 2011), também permitiram colocar elementos para a construção uma ferramenta on-line de auxílio à escrita simplificada, graduada por perfis de leitores. Essa é a "Ferramenta MedSimples", ainda em construção.

Nossa ferramenta, como será fácil perceber, é muito inspirada no já citado sistema SIMPLIFICA (ALUÍSIO; GASPERIN, 2010). Esse recurso tem como diferencial, além da singeleza do seu sistema computacional, o fato de funcionar por temáticas bastante específicas. Uma parte da ferramenta já pode ser consultada em http://www.ufrgs.br/ textecc/acessibilidade/page/cartilha/.

A Figura 5, a seguir, ilustra uma das funcionalidades do sistema MedSimples. Vale salientar, a propósito, que lidamos apenas com o nível do léxico, com listas de palavras, listas de termos e com o repertório de itens do CorPop.

A complexidade frasal ou sintática, em meio à ferramenta, ainda é um robusto ponto de estudos a enfrentar, considerando-se um tratamento automatizado. Entretanto, já estamos oferecendo uma funcionalidade com exemplos de frases mais ou menos complexas no item "Coleção de Frases". E, para dar conta desse aspecto, ainda a descoberto, imaginamos que será possível colher boas evidências sobre fraseamentos do tipo muito complexo=>complexo=>simples a partir do trabalho em andamento com as sentenças judiciais dos JECS. Afinal, parece ser comum que essas sentenças exibam frases bastante "peculiares" e sintaticamente muito complexas, mesmo para um leitor que seja um linguista experiente. 


\section{Simplificação sugerida}

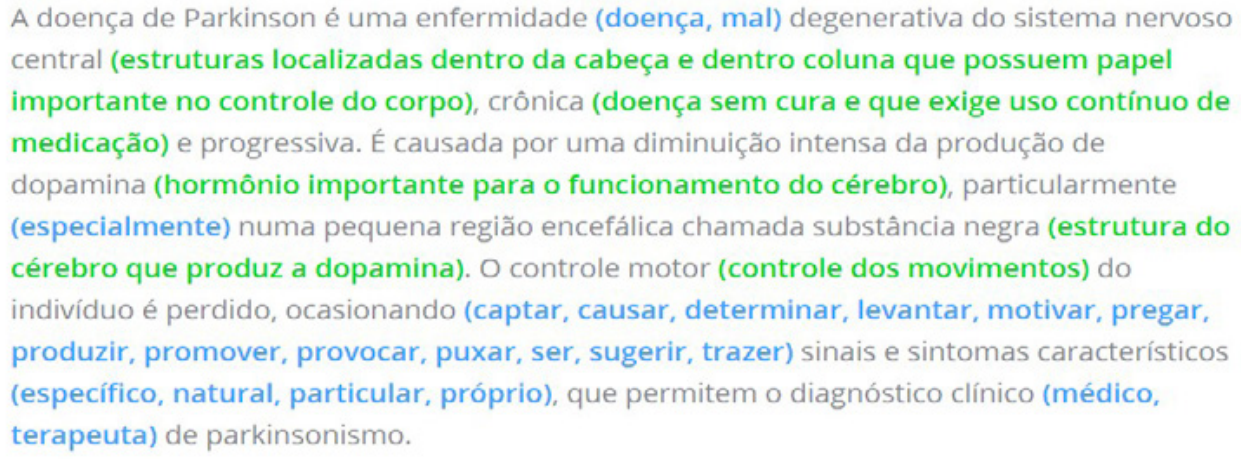

Figura 5. Parte da ferramenta de auxílio à escrita simplificada com um exemplo de texto a ser simplificado

Fonte: http://www.ufrgs.br/textecc/acessibilidade/page/cartilha/

Em paralelo, desde o trabalho de Paraguassu (2018), foi possível pensar em uma proposta de ensino, uma alternativa de disciplina ou de um módulo de estudos especialmente dedicado aos temas da ATT em meio às grades curriculares de cursos que formam tradutores no Brasil. Afinal, nesse cenário, o profissional tradutor com formação no assunto e com conhecimentos de Terminologia poderá desempenhar a função de um "profissional simplificador" de textos, traduzindo de um "português complexo" para um "português facilitado". Nesse trabalho, temos a tradução interlinguística e a intralinguística aproximadas e contrastadas.

Além disso, prosseguimos fazendo alguns estudos com textos do MS sobre o tema da Sífilis, os quais têm reunido estudantes de graduação e doutorandos. Conforme notícias recentes de jornal da nossa cidade, desde 2016, infelizmente, o número de casos da doença aumentou em mais de $26 \%$. A nosso pedido, recebemos do MS, em 2018, os materiais produzidos até 2018 para público leigo, que já estamos examinando, em cotejo com materiais institucionais sobre a Doença de Parkinson. A sífilis que atinge bebês, no âmbito da Pediatria, é a que mais nos interessa, pelo foco de pesquisa com apoio do $\mathrm{CNPq}^{5}$. Não sabemos, entretanto, se esse tema específico poderá ser incluído na Ferramenta MedSimples antes citada.

5 CNPq - Edital Universal - Processo: 403521/2016-5. Mais detalhes em: http://www.ufrgs.br/ textecc/acessibilidade/. 
Por fim, vale, ainda, o registro de nossas duas mais recentes frentes de estudo. Uma delas é com textos antigos de Medicina em português que foram escritos para, em tese, serem acessíveis para pessoas de pouca "erudição". O diferencial dessa investigação é, além do estudo diacrônico das terminologias, o fato de estarmos lidando com uma obra que foi impressa em Portugal, no século XVIII. Como a sua proposta era a de dar acessibilidade para quem, naquela época, atendia doentes, sabia ler, mas não sabia Latim, nem era erudito, colocou-se mais um cenário para a nossa reflexão sobre a ATT. Nessa iniciativa, estamos organizando um corpus-amostra composto por obras impressas em português do século XVIII relacionadas ao macrotema "doenças e seus tratamentos". Mais detalhes podem ser conferidos em http://www.ufrgs.br/textecc/terminologia/ e no nosso artigo (FINATTO, 2018).

A segunda e mais nova temática de pesquisa do nosso grupo tem a ver com o que se poderia denominar de "acessibilidade da acessibilidade", visto que passamos a trabalhar com padrões de simplificação para materiais em Libras. Nesse cenário, oferecer um texto sobre um tema de Saúde traduzido em Libras é um primeiro estágio da informação acessível. O segundo estágio estará associado ao oferecimento da informação em um "vocabulário simples", frisamos, de/em Libras, com sinais mais usuais e sinais-termo. O tratamento de conteúdos técnico-científicos em Libras (TUXI; FELTEN, 2019) é um dos mais novos desafios para os estudos de terminologia e de Terminografia no Brasil. A propósito, pelo que temos observado, a tradução de um texto para Libras tenderia a render um texto "naturalmente mais simples", o que poderia ser conferido pelas legendas em português que acompanham a sinalização filmada. Aproximar essas legendas considerando a ST do material-fonte escrito em português e sua "tradução reversa" é uma ideia diferenciada, de nossa autoria, que pretendemos desenvolver.

Os desafios desse tipo de trabalho são múltiplos, haja vista a complexidade dos temas da CT ou da ST. Fora isso, infelizmente, ainda hoje, muitas pessoas - inclusive pesquisadores de Letras - manifestam pré-julgamentos sobre a acessibilidade ou sobre processos de simplificação, alegando que, em termos de compreensão de leitura, oferecer textos simplificados, sem terminologias, seria "nivelar por baixo". Afinal, conforme apontam, o ideal é que todos pudessem ter conhecimentos para entender mensagens "simples" como são as do MS ou a Sentenças dos JECS. De nossa parte, defendemos que ao lado das terminologias, que são marcas do conhecimento científico, merecem estar algumas facilitações. Do mesmo modo, vale repetir, nem só de "termos técnicos" é feita a CT.

Independentemente de julgamentos, acreditamos que a temática em foco, especialmente a da promoção da ATT, seja ela entendida como qualidade ou um ideal, como um tópico de pesquisa no âmbito da Terminologia e da Linguística Aplicada ou "apenas" uma demanda social, merece ser divulgada e entendida como algo legítimo. Muito já avançamos, e cada vez mais as instituições têm que prestar mais atenção na qualidade do texto e da informação que oferecem para o "cidadão comum". O próprio MS já tem melhorado 
muito os textos que nos oferece, sendo um exemplo a informação sobre a "Doença de Parkinson" disponível em http://bvsms.saude.gov.br/dicas-em-saude/2059-doenca-deparkinson - acesso em 21 out. 2019 - e que contou com insumos da Associação Brasil Parkinson - uma associação de pessoas com Parkinson - e do Dr. Dráuzio Varela, para nós uma referência brasileira em empatia e em facilitação de informações sobre Saúde.

Entretanto, ainda há muito a ser feito. Há muitos casos em que o analista linguista ou terminológo envolvido com a ATT precisará ponderar sobre o uso de terminologias em excesso, sendo sempre necessário ir além. É preciso estar atento para o emprego de diversos outros elementos, tais como, recursos coesivos, referenciações, além dos variados elementos vocabulares e sintáticos mais ou menos "eruditos" de um discurso especializado. Tudo isso demandará uma "tradução", necessidade que parece ficar mais ainda mais evidente quando observamos um texto jurídico. Por isso, deixamos para o nosso leitor, dois trechos desafiadores, cada um ao seu modo, que tratam, justamente, de Saúde e de Direito.

Logo, não há na legislação critérios objetivos que estabeleçam um tarifamento indenizatório, mas fica ao arbítrio do julgador dosar os elementos que configuraram a lesão para se fixar o quantum, levando-se em conta algumas indicações como: gravidade do dano, extensão do dano, grau de culpa do ofensor, situação econômico-financeira das partes e fator dissuasório da sanção.

(Trecho de Sentença judicial, JEC, "Tribunal de Pequenas Causas")

O tratamento da paralisia facial periférica é sintomático e inclui o uso de medicamentos, fisioterapia e fonoaudiologia. Não existe, entretanto, uma conduta terapêutica padrão para a doença. Tudo depende do tipo e da extensão do dano sofrido pelo nervo facial, das condições clínicas e da idade do paciente. Em grande parte dos casos, a paralisia facial periférica costuma regredir sem tratamento, à medida que o inchaço do nervo diminui espontaneamente. Durante todo o tratamento, os olhos exigem atenção especial. Como os pacientes apresentam dificuldade para fechar os olhos e menor produção de lágrimas, a aplicação de colírios lubrificantes (lágrimas artificiais), várias vezes por dia, assim como o uso de tampões para manter o olho fechado, são medidas indispensáveis para manter o olho hidratado e evitar lesões graves na córnea.

(Trecho de "Paralisia facial", em Dicas em Saúde do MS, disponível em http:// bvsms.saude.gov.br/dicas-em-saude/2571-paralisia-facial)

Fica, por fim, o convite para cooperação aos interessados nesse tipo de pesquisa, seja em Linguística Aplicada, Teoria e Análise Linguística, Estudos do Texto e do Discurso, em Terminologia, em estudos sobre Libras ou em quaisquer outras áreas. O convite estende-se também aos colegas de Ciência da Computação e de Educação em Saúde. 
Em tempos em que enfrentamos uma pandemia global, a necessidade da acessibilidade das informações de Utilidade Pública para todas as pessoas parece ser algo imediato, essencial e que convoca também os pesquisadores de Terminologia. Assim, esperamos que diferentes estudiosos possam considerar viáveis ou motivadoras quaisquer das possibilidades de estudos e de diálogos aqui mencionadas ou subentendidas.

\section{Agradecimentos}

Os trabalhos aqui mencionados só puderam existir por conta do empenho de vários colegas, alunos e orientandos, e graças ao apoio dos seguintes órgãos e programas de fomento à pesquisa: CNPq, programas PQ 2016 e 2019; CAPES/FAPERGS, Edital 06/2018 Internacionalização, SEAD-UFRGS, Prêmio LARA 2019 (Google), CAPES e PPG-LETRASUFRGS.

\section{REFERÊNCIAS}

ALUÍSIO, S. M.; GASPERIN, C. Fostering Digital Inclusion and Accessibility: The PorSimples project for Simplification of Portuguese Texts. Proceedings of the NAACL HLT 2010 Young Investigators Workshop on Computational Approaches to Languages of the Americas, New York: ACL, v. 1, p. 46-53, 2010.

BARROS, L. A. BARROS. Curso Básico de Terminologia. EdUSP, São Paulo, 2004.

BIDERMAN, M. T. C. Léxico e Vocabulário Fundamental. Alfa, São Paulo, v. 40, p. 27-46, 1996.

BIDERMAN, M. T. C. Teoria Linguística: Linguística Quantitativa e Computacional. Rio de Janeiro: Livros Técnicos e Científicos, 1978.

BIDERMAN, M. T. C. Estatística linguística. Alfa, São Paulo, v. 11, p. 117-128, 1967.

CARPIO, P. M. S. Abaixando o cocho: adaptação de textos sobre doenças causadas pela inalação de amianto destinados para o público leigo. 2017. Trabalho de Conclusão de Curso (Bacharelado em Letras) - Instituto de Letras, Universidade Federal do Rio Grande do Sul, Porto Alegre, 2017.

DUBAY, W. H. The Principles of Readability. 25 August 2004. Disponível em: http://www. impact-information.com/impactinfo/readability02.pdf. Acesso em: 21 out. 2017. 
FETTER, G. L. Acessibilidade textual para agricultores familiares: análise sistêmicofuncional da terminologia. Revista Inventário, Salvador, n. 21, p. 19-34, jul. 2018.

FETTER, G. L. Divulgação tecnológica para agricultores familiares: análise de terminologias sob a ótica da Linguística Sistêmico-Funcional. 2017. Dissertação (Mestrado) - Instituto de Letras, Universidade Federal do Rio Grande do Sul, Porto Alegre, 2017.

FINATTO, M. J. B. Corpus-amostra português do século XVIII: textos antigos de Medicina em atividades de ensino e pesquisa.Domínios de Lingu@gem, Uberlândia, v. 12, n. 1, p. 435464, mar. 2018. Disponível em: http://www.seer.ufu.br/index.php/dominiosdelinguagem/ article/view/40004. Acesso em: 21 out. 2019.

FINATTO, M. J. B. Complexidade textual em artigos científicos: contribuições para o estudo do texto científico em português. Organon, Porto Alegre, v. 25, n. 50, p. 67-100, jan./jun. 2011.

FINATTO, M. J. B. Termos, textos e textos com termos: novos enfoques dos estudos terminológicos de perspectiva linguística. In: ISQUERDO, A. N.; KRIEGER, M. G. (org.). As ciências do léxico: lexicologia, lexicografia, terminologia. v. 2. Campo Grande: Ed. UFMS, 2004. p. 341-358.

FINATTO, M. J. B.; PONOMARENKO, G. L.; BERWANGER, L. P. Não basta ler, tem que entender: simplificando textos. Revista Roseta - ABRALIN, v. 2, n. 1, 2019. Disponível em: www.roseta.org.br. Acesso em: 20 set. 2019.

FLESCH, R. The Art of Readable Writing. New York, Evanston: Harper \& Row Publishers, 1949.

FULGÊNCIO, L.; LIBERATO, Y. Como facilitar a leitura. 3. ed. São Paulo: Contexto, 1998.

INAF 2018 - AÇÃO EDUCATIVA; INSTITUTO PAULO MONTENEGRO. (2018). Indicador de Alfabetismo Funcional (INAF BRASIL 2018): resultados preliminares. São Paulo: Ação Educativa; IPM.

JAKOBSON, R. On linguistic aspects of translation. In: VENUTI, L. (ed.). The Translation Studies Reader. London: Routledge, 2012 [1959]. p. 126-131.

KRIEGER, M. da G.; FINATTO, M. J. B. Introdução à Terminologia: teoria e prática. 2. ed. [reimpressão]. São Paulo: Contexto, 2017. 
LEFFA, V. J. Fatores da compreensão na leitura. Projeto ELO, Ensino de Línguas Online: 1996. Disponível em: www.leffa.pro.br. Acesso em: 20 out. 2019.

MIRANDA, V. da C. et al. Como consentir sem entender? Rev. Assoc. Med. Bras., São Paulo, v. 55, n. 3, p. 328-334, 2009. Disponível em: http://www.scielo.br/scielo.php?script=sci_ arttext\&pid=S0104-42302009000300028\&lng=en\&nrm=iso. Acesso em: 10 out. 2019.

MOTTA, E. Índices de complexidade textual em Sentenças dos Juizados Especiais Cíveis do poder judiciário do Estado do Rio Grande do Sul. Revista Inventário, Salvador, n. 21, p. 19-34, jul. 2018.

MOTTA-ROTH, D.; SCHERER, A. S. Popularização da ciência: a interdiscursividade entre ciência, pedagogia e jornalismo. Bakhtiniana, Revista de Estudos do Discurso, São Paulo, v. 11, n. 2, p. 164-189, mar. 2016. Disponível em: http://revistas.pucsp.br/index.php/ bakhtiniana/article/view/23671. Acesso em: 21 out. 2018.

PARAGUASSU, L. B. Tradução especializada acessível (TEA): revisão do tema e proposta de disciplina para cursos de graduação em tradução. 2018. Dissertação (Mestrado) Instituto de Letras, Universidade Federal do Rio Grande do Sul, Porto Alegre, 2018.

PASQUALINI, B. F. CORPOP: um corpus de referência do português popular escrito do Brasil. 2018. Tese (Doutorado em Letras) - Instituto de Letras, Universidade Federal do Rio Grande do Sul, Porto Alegre, 2018.

PEREIRA, V. W.; BARETTA, D. Compreensão literal e inferencial em alunos do Ensino Fundamental. Signo, Santa Cruz, v. 43, p. 53/77-61, 2018.

PERINI, M. A. Tópicos discursivos e legibilidade. In: PERINI, M. A. (coord.). Definição linguística da legibilidade. Belo Horizonte: Relatório de Pesquisa ao Inep, 1982.

SCARTON, C. E.; ALUÍSIO, S. M. Análise da Inteligibilidade de textos via ferramentas de Processamento de Língua Natural: adaptando as métricas do Coh-Metrix para o Português. Linguamática (Revista para o Processamento Automático das Línguas Ibéricas), Porto, v. 2, n. 1, p. 45-61, 2010. Disponível em: http://linguamatica.com/index. php/linguamatica/article/viewfile/44/59. Acesso em: 21 out. 2019.

SILVA, A. D. C. Textos de divulgação para leigos sobre o transtorno do estresse pós-traumático em português: alternativas para a acessibilidade textual e terminológica. 2018. Dissertação (Mestrado em Letras) - Instituto de Letras, Universidade Federal do Rio Grande do Sul, Porto Alegre, 2018. 
TUXI, P.; FELTEN, Eduardo F. Terminologia, terminografia e línguas de sinais. Revista do IEEE América Latina, v. 1, p. 134-152, 2019.

ZETHSEN, K. Intralingual Translation: An Attempt at Description. Meta, Montreal, v. 54, n. 4, p. 795-812, 2009.

ZETHSEN, K. K.; HILL-MADSEN, A. Intralingual Translation and Its Place within Translation Studies - A Theoretical Discussion, Meta, Montreal, v. 61, n. 3, p. 692-708, dez. 2016. 